\title{
Ludwig Wittgenstein y Observaciones a los cuadernos de Gramsci: una ficción filosófica
}

Silvia Adriana Rivera*

Profesora de Filosofía, Universidad de Buenos Aires, Buenos Aires, Argentina. Correo electrónico:

silviarivera@ar.inter.net

Recibido: 28 de abril del 2015

Aprobado: 15 de junio del 2015

Cómo citar este artículo: Rivera, Silvia Adriana. "Ludwig Wittgenstein y Observaciones a los cuadernos de Gramsci: una ficción filosófica". Rastros Rostros 17.31 (2015): 143-150. Impreso. doi: http://dx.doi. org/10.16925/ra.v17i31.1100

\section{Resumen}

Propósito: este artículo es un ejercicio de "filosofía fantástica", en el cual se concibe la escritura de un libro imaginado: Observaciones a los Cuadernos de Gramsci. Temas: desde el espacio inasible de los confines y las fronteras entre lo literario y lo filosófico, lo real y lo ficticio, lo necesario y lo posible-, se reconstruye un texto que propicia el encuentro de dos pensadores: Wittgenstein y Gramsci. Desarrollo: un encuentro quizás inexistente, pero no del todo imposible. Un encuentro que permite resignificar la obra de Wittgenstein a partir de las marcas que la lectura de Gramsci imprime a su tradicional preocupación por el lenguaje, orientando la filosofía terapeútica hacia una teoría de la praxis. Conclusiones: así se enriquece el espectro de alternativas que Wittgenstein lega, en especial en el campo de la teoría social, la cual se expande al ser investida por un franco compromiso ético-político.

Palabras clave: ficción filosófica, filosofía de la praxis, Ludwig Wittgenstein, teoría social, usos del lenguaje. 


\title{
Ludwig Wittgenstein and Observaciones a los cuadernos de Gramsci: A Philosophical Fiction
}

\begin{abstract}
Purpose: this article is an exercise of "fantastical philosophy" in which the writing of an imagined book - Observaciones a los Cuadernos de Gramsci- is conceived. Topics: from the elusive space of confines and borders - between literature and philosophy, reality and fiction, need and possibility-, a text that facilitates the encounter of two thinkers -Wittgenstein and Gramsci- is rebuilt. Development: perhaps a nonexistent, but not at all impossible encounter. An encounter that allows to re-define Wittgenstein's work from the marks that Gramsci's reading gives to his traditional concern for language, directing therapeutic philosophy towards a theory of praxis. Conclusions: thus, the range of alternatives that Wittgenstein bequeathed is enriched, especially in the field of social theory, which has expanded upon being invested by a frank ethical-political commitment.
\end{abstract}

Keywords: philosophical fiction, philosophy of praxis, Ludwig Wittgenstein, social theory, uses of language.

\section{Ludwig Wittgenstein e Observações aos cadernos de Gramsci: uma ficção filosófica}

\section{Resumo}

Propósito: este artigo é um exercício de "filosofia fantástica", onde se concebe a escritura de um livro imaginado: Observações aos Cadernos de Gramsci. Temas: desde o espaço que não se pode segurar e das fronteiras - entre o literário e o filosófico, o real e o fictício, o necessário e o possível-, reconstrói-se um texto que propicia o encontro de dois pensadores: Wittgenstein e Gramsci. Desenvolvimento: um encontro talvez inexistente, mas não totalmente impossível. Um encontro que permite dar um novo significado à obra de Wittgenstein a partir das marcas que a leitura de Gramsci imprime a sua tradicional preocupação pela linguagem, voltado a filosofia terapêutica para uma teoria das práxis. Conclusões: é assim que se enriquece o leque de alternativas que Wittgenstein herda, especialmente no campo da teoria social, a qual se expande ao ser investida por um franco compromisso ético-político.

Palavras-chave: ficção filosófica, filosofia da práxis, Ludwig Wittgenstein, teoria social, usos do linguaje. 
Toda nuestra llamada conciencia es un comentario, más o menos fantástico sobre un texto desconocido, quizás imposible de conocer, pero sentido.

Federico Nietzsche, Aurora.

Cada ser clama en silencio pidiendo ser leído de otra manera. No hagamos oídos sordos a sus

gritos.

Simone Weil, Cuadernos.

Cerró el libro suavemente, con un franco gesto de satisfacción en el rostro. Y su mano comenzó a deslizarse por la tapa y la contratapa, sus dedos lo recorrieron con suavidad primero y con voracidad después, como si dudando de sus ojos necesitara todavía reconocer la obra con la piel. Reconocerla propia, aun cuando el nombre de Wittgenstein lo interpelara desde esas letras oscuras que se recortaban con firmeza en el fondo color marfil. Sin duda un diseño sobrio, tal como lo requería la relevancia académica del texto que allí se presentaba. Relevancia que lo convertía en algo semejante a un acontecimiento - diría tal vez Badiou-, y como tal exigía fidelidad para sostener su dimensión originaria y fundante. Esto pensaba en los minutos previos a la presentación del libro, mientras parpadeaba con cierto nerviosismo, como si quisiera alejar una nube inesperada, un pensamiento incómodo. Después de todo, casi nada del pobre hombre quedaba sin entregar a los insaciables hermeneutas que esperaban con impaciente avidez la oportunidad de despedazar esta nueva presa, por él rastreada y compilada. La nueva presa que un emporio editorial lanzaba ahora al mercado. Se habían expuesto diarios íntimos que contenían confesiones de deseos prohibidos y toda clase de mezquindades vergonzantes o no tanto, todo dependía de la rigurosidad o hipocresía de los parámetros utilizados para juzgarlas. Pero vergonzantes o no, de intimidades se trataba. Sin embargo, esto era diferente; se tranquilizó, porque no había en estas páginas registros de masturbaciones compulsivas, de soberbias mal disimuladas, de desprecios e impaciencias, o desgarrantes tensiones entre la vida y la muerte. ¿Por qué entonces esa incomodidad que lo agobiaba? ¿Por qué a pesar suyo algo le parecía obsceno? Quizás, porque la exposición era ahora completa: notas de clase, apuntes, cartas, comentarios de conversaciones oídas o inventadas, con citas de fuentes o sin ellas.
Un hombre estudiado en los límites de sus razones y sus deseos. Un hombre desarmado y reconstruido otra vez, como tantas veces, de acuerdo con pautas varias, diferentes, aun contradictorias, excluyentes. Wittgenstein kantiano o analítico. Wittgenstein místico, empirista, escéptico. Ludwig Wittgenstein: modelo para armar.

Recordó entonces cómo tras las huellas de Domique Lecourt (169) se había lanzado a esta aventura, hacía ya tanto tiempo. De Lecourt y algunos otros que se animaron a explorar acercamientos poco convenientes entre tradiciones, desafiando las pautas establecidas con claridad en la lectura promovida desde la academia. Wittgenstein y Marx arriesgó Ferruccio Rossi-Landi (11), y fue quizás esta audacia la que en su tiempo contribuyó a reforzar ese rótulo de "filósofo menor" que se adjunta todavía al nombre del pensador italiano. Wittgenstein y Nietzsche propuso por su parte Massimo Cacciari (1982 108), poco antes de priorizar la política a los interminables ejercicios hermenéuticos.

Sin embargo, se trataba en estos casos de acercamientos construidos a partir de teorizaciones que no pretendían validarse con la evidencia de efectivas influencias. Por el contrario, otros autores sí habían hurgado en las huellas de encuentros posibles, pero mediados por terceros que oficiaron de canales transmisores en uno $\mathrm{u}$ otro sentido. WittgensteinKuhn vía Stanley Cavell como años atrás expuso Alberto Moreno (560), con su tonada cordobesa. O Wittgenstein-Gramsci a través de Piero Sraffa, quien en los años treinta habría explicado las ideas de su amigo encarcelado a un Wittgenstein instalado una vez más en las habitaciones del Trinity College, según se lee en la exhaustiva biografía de Ray Monk (314). Wittgenstein y Gramsci: este fue su desafío, pero no para plantear la relación en términos de acercamientos posibles o mediados, sino a través de encuentros textuales perfectamente reconstruibles en sus detalles mínimos y confrontados con las palabras exactas de por lo menos uno de sus protagonistas.

Recordó también su incansables días en el archivo. Sus recorridos no siempre pacientes por el Nachlass, nombre con el que se identifican los textos no publicados por Wittgenstein: notas manuscritas que siguen el curso espontáneo de sus pensamientos y también escritos mecanografiados en diversos estados de revisión. Partes significativas de este Nachlass, muy especialmente las Investigaciones filosóficas, se parecen a algo que Wittgenstein podría haber publicado. Otras partes, por el contrario, se articulan 
en una serie de fragmentos independientes, más o menos breves, sobre temas o libros que en algún momento oficiaron como detonantes de las reflexiones del filósofo.

Fue en los renglones y en los márgenes de estos manuscritos que buscó con terquedad el nombre de Gramsci. Y creyó encontrarlo en ocasiones, para verlo después desvanecerse entre otras letras que diagramaban grafías semejantes. Lo buscó siguiendo intuiciones propias y palabras ajenas. Las palabras de la hija de Fania Pascal, a quien él había entrevistado. El recuerdo de Wittgenstein escrito por Fania Pascal (43 y ss.) en 1969, no se destacaba entre otras tantas memorias ni por la agudeza de su perspectiva, ni por el brillo de su estilo. A pesar de esto había convocado su atención de un modo especial, quizás debido a dos anotaciones muy precisas allí consignadas. La primera de ellas deja constancia del asombro de Fania por la escasez o hasta ausencia de referencias a Francis Skinner y a Nicholas Bachtin en las abundantes y abultadas biografías de Wittgenstein, las cuales por esos años - escritas por amigos, alumnos y familiares - se multiplicaban por doquier. Estos dos hombres, por motivos diversos, habían estado muy cerca de Wittgenstein en la década del treinta y Fania lo sabía. Francis, un joven humilde y enfermizo, fue su compañero y amante. Nicholas ${ }^{1}$, un académico apasionado que dedicaba sus días al estudio de las letras clásicas, fue su opositor en discusiones interminables.

La segunda anotación que concertó su atención - en cierta forma contradictoria con la primera-, expresa la incomodidad de Fania ante la exposición excesiva de la vida de un hombre, ya sea guiada por intereses literarios, filosóficos o personales (incluso mezquinos). En especial cuando ese hombre se dedicó a construir, desde el más estricto pudor, tan compactas defensas. "Nadie puede escribir una serie de recuerdos personales sobre Wittgenstein sin sentir de inmediato, de manera casi física, su mirada de reproche y reprobación" (43), dice Fania al comenzar su relato. Es probable que esa mirada de reprobación y reproche la acompañara hasta su muerte.

Fania Pascal, autora del citado recuerdo de Wittgenstein, había llegado a Cambridge en 1930 después de obtener en Berlín su doctorado en filosofía y asistir, durante algunos meses, a las reuniones del Moral Science Club presididas por G. E. Moore. En Un recuerdo personal cuenta Fania su primer encuentro

Nicholas Bachtin fue el hermano de Mijail Bajtin, el semiólogo ruso que sufrió persecuciones durante la dictadura de Stalin. con Francis, quien hacia fines del otoño de 1933 se presentó en su casa para preguntarle si podría darle lecciones de ruso. Al decirle ella cuánto le cobraría por las clases, Francis preguntó si por la misma paga podría asistir también un amigo. Fania asintió y en señal de agradecimiento recibió en días siguientes una hermosa planta que prologó el primer encuentro, signado, en verdad, por la profunda sorpresa que le produjo advertir que el amigo de Francis era nada menos que el ya célebre Ludwig Wittgenstein (47).

Acerca de Nicholas Bachtin, cuenta Fania que se trataba de un exiliado de la revolución rusa pero comunista de corazón, a quien Wittgenstein quería entrañablemente. Remontando su habitual sobriedad, Wittgenstein se mostraba muy alegre en presencia de Bachtin, y esto a pesar de sus diferentes carácteres y apariencias. Bachtin era dado a pasiones extremas que expresaba con libertad y que en ningún caso intentaba controlar. Por el contrario, el rigor de Wittgenstein lo obligaba a una exagerada vigilancia de sus expresiones, en un sostenido intento de resguardar la completa intimidad de emociones y sentimientos.

Quizás fue el expreso asombro de Fania ante el ocultamiento de la relación íntima entre el siempre abrumado Wittgenstein y el tímido Skinner - a quienes conocía bien por haber compartido con ellos tardes amables de esforzado aprendizaje, cenas familiares y noches de teatro-, aquello que la impulsó a buscar a la hermana de Francis tiempo después, iniciando con ella una amistad que se extendería varios años. Fue la señora Truscott, hermana de Francis, quien entregó a Fania un libro y un manuscrito, ambos encontrados entre las pertenencias de su hermano. Un ejemplar de Crimen y castigo - la lectura favorita de Wittgenstein en ruso-, en la que podían distinguirse todavía los acentos marcados con lápiz por el filósofo y unas treinta páginas amarillentas y algo arrugadas que tenían por título Observaciones a las anotaciones de Gramsci.

En su recuerdo personal, Fania menciona el libro pero nada dice del manuscrito que había ardido entre sus manos mientras desesperadamente intentaba buscar un destino justo para él, tal como le contó con prolijos detalles su hija aquella tarde de la entrevista. Aunque de ningún modo era ella quien debía decidir esto, pronto se tranquilizó Fania ya que después de todo había albaceas especialmente designados para administrar el legado intelectual de Wittgenstein. Fue a ellos entonces a quienes entregó el trofeo, no sin ciertas vacilaciones que surgían tal vez de su asombro ante 
el ocultamiento no casual de esa otra relación, la que existió entre Wittgenstein y Bachtin. Vacilaciones que resultaron moderadamente aplacadas por el tono profesional de aquellos académicos que aseguraron anexar el manuscrito al Nachlass hasta que se evaluara con cuidado la pertinencia de su publicación. Pero todo hace suponer que, si evaluación hubo en efecto, esta no dictaminó pertinencia, ya que el tiempo pasó y el posible vínculo entre Wittgenstein y Gramsci se mantuvo en ese difuso nivel de insinuaciones de tono un tanto trasnochado y sospechosas de responder a intereses poco transparentes.

Ese manuscrito convertido en un libro que juzgaba hermoso, se encontraba por fin entre sus manos. El manuscrito - que había rastreado en revisiones interminables del Nachlass, sosteniendo sus desvelos en las palabras de la hija de Fania, que le acercaban a su vez aquellas otras palabras de su madre, confirmando la existencia del texto-, se presentaba ese día en versión revisada y bilingüe, precedida por una extensa introducción que él había escrito. Se trataba, sin duda - se dijo a sí mismo quizás en un renovado intento de justificación-, de una obra decisiva que enriquecía su significado al desplegarlo en planos diversos. Porque no solo acercaban sus páginas las claves necesarias para revitalizar la lectura de Wittgenstein, y muy especialmente para identificar en ella nuevos rumbos heurísticos, sino que oficiaba también como instancia reinvindicatoria de más de un wittgensteiniano marginado.

$\mathrm{Su}$ pensamiento se detuvo entonces, por unos minutos, en el primero de los planos señalados, a fin de repasar algunas de esas claves y también de esos rumbos. Claves y rumbos que resultan iluminados a partir de la identificación precisa de aquellos fragmentos de los escritos de Gramsci que habían sido leídos y comentados por Wittgenstein. Porque está claro que Wittgenstein no pudo leerlos completos, considerando que la edición definitiva de los Cuadernos de cárcel se postergó hasta varios años después de la muerte de Gramsci, acontecida en abril de 1937, seis días después de haber cumplido su condena, rebajada por una amnistía parcial ${ }^{2}$.

Precisar los fragmentos leídos por Wittgenstein no le resultó difícil, ya que con frecuencia el filósofo anteponía a sus observaciones - numeradas

\footnotetext{
2 Después de la muerte de Gramsci los cuadernos son llevados a Moscú. A fines de 1938 llegan a manos de Palmiro Togliatti y después de la guerra vuelven a Italia, donde se inicia la etapa de su publicación.
}

consecutivamente - la transcripción exacta de aquellas palabras de Gramsci que las habían inspirado³. Palabras de Gramsci que en su mayor parte expresaban agudas críticas al dogmatismo metafísico contenido en el materialismo vulgar que, con pretensiones científicas, había presentado Bujarin en su Ensayo popular de sociología. Tampoco le resultó difícil explicar cómo habían llegado hasta Wittgenstein estos fragmentos posteriormente recopilados bajo el título Notas críticas sobre un intento de "Ensayo popular de sociología". Las referencias a las reuniones semanales que a partir de 1929 y durante muchos años compartieron Wittgenstein y Sraffa, se habían multiplicado significativamente en las biografías del filósofo publicadas en las últimas décadas. La impronta que el pensamiento de Sraffa dejara en su obra se hace manifiesta en el prefacio a las Investigaciones filosóficas. Allí dice Wittgenstein, acerca de las reuniones compartidas con Sraffa: "Las ideas más importantes de este libro están en deuda con ese estímulo" (13).

Piero Sraffa fue un brillante economista italiano que se estableció en Cambridge en 1927, invitado por Keynes para proseguir allí su trabajo luego de un ataque público a la política de Mussolini que puso en peligro su carrera en Italia. Fiel amigo de Gramsci, no solo lo visitó en ocasiones en la cárcel, sino que desplegó fondos y contactos personales para proveerlo de libros, periódicos y otros elementos indispensables para la redacción de sus cuadernos, recibiendo en ocasiones, y a través de estos mismos contactos, algunas de las páginas redactadas. De las innumerables páginas redactadas, porque en sus oscuros días en la cárcel de Turi, cerca de Bari, Gramsci completó con una escritura maniáticamente prolija treinta y tres cuadernos escolares, equivalentes aproximadamente a cuatro mil páginas mecanografiadas.

La prueba contundente de que Sraffa había compartido con Wittgenstein la lectura de esas páginas pronto se presentaría al público, con formato de libro y rubricada con la firma del filósofo. La prueba por él rescatada de las oscuridades del archivo. Pasados ya los tiempos de especulaciones sobre influencias inciertas ve abrirse ante sus ojos nuevos caminos para investigaciones sistemáticas acerca del significado y alcance de la "filosofía terapeútica". Esto piensa, mientras con la expresión contundente de su

Algo semejante ocurre con el texto de Wittgenstein Observaciones a la Rama Dorada de Frazer; si bien en este caso las referencias al texto de Frazer no son textuales y los editores optaron por transcribirlas literalmente como notas a pie de página. 
rostro reafirma la firmeza de sus convicciones. El significado y alcance de la filosofía terapéutica revisado en función de sus aplicaciones al campo de la teoría social. Una teoría social "crítica y transformadora" - como había elegido calificarla en la introducción que con tanto esmero había escrito para presentar las Observaciones a los Cuadernos de Gramsci-, la cual previera entre sus capítulos el análisis explícito de sus propias condiciones de cientificidad. Porque la definición del método propio de la teoría social y también la determinación de sus objetivos específicos, se imponen como condiciones necesarias para la refutación de todo intento reduccionista. Pero ante todo, una primera delimitación: la del objeto de estudio de esta teoría no reduccionista de lo social, tal como lo había expresado Wittgenstein en la observación número veinticinco, que buscó entre todas las otras observaciones y leyó casi con la misma emoción que en otros tiempos había coloreado la primera lectura:

El problema de la sociología parece surgir de la falta de precisión en la definición de su objeto, que la lleva hacia inconvenientes asimilaciones. Sin embargo creo que ese objeto no puede ser otro que el lenguaje. ¿Pero qué quiere decir aquí "lenguaje"? (Observaciones 16)

De acuerdo con su peculiar modo de analizar un problema, volviendo a él una y otra vez desde perspectivas diversas, Wittgenstein retomó en posteriores observaciones la cuestión de los límites de una sociología de corte positivista. En la observación número treinta y siete, por ejemplo, se lee:

Dice Gramsci: "Si se observa bien, se ve que en el Ensayo popular falta el concepto claro y preciso de lo que es la propia filosofía de la praxis". Pero no está claro todavía si la praxis es aquí el objeto de la filosofía o la filosofía es práctica de análisis del lenguaje. En todo caso, cabe preguntar todavía si filosofía es el nombre que conviene a esta práctica.

Gramsci dice "filosofía" pero quiere tal vez decir "sociología", aunque con resonancias distintas a las que este término tiene en ciertos contextos. La intención de sus críticas es la redefinición completa de aquello que se entiende por sociología. Sin duda es esta una cuestión de lenguaje. (21)

En este punto, el curso de sus pensamientos lo condujo una vez más a Cambridge, hasta los años posteriores al regreso de Wittgenstein en 1929, signados por el ritmo vertiginoso de la vida intelectual y social. Mientras cada semana discutía con Piero Sraffa estos y otros pasajes de las anotaciones de Gramsci, Wittgenstein se reunía para revisar áridas cuestiones de lógica matemática con el joven y talentoso Frank Ramsey. A comienzos de 1934 y junto con Francis Skinner, comenzó a tomar lecciones de ruso al tiempo que planificaba con ilusión y detenimiento un viaje a la Unión Soviética, ayudado en este emprendimiento por sus amigos Nicholas Bachtin, John Maynard Keynes y Maurice Dobb, entre otros. Este viaje se concretó finalmente en septiembre de ese mismo año, y si bien a su regreso se mostró poco dispuesto a la manifestación pública de sus opiniones, comentó a sus allegados que regresaría en un par de años, tal vez para establecerse definitivamente, atenuando además la improcedencia de la tiranía de Stalin con las siguientes palabras:

La gente ha acusado a Stalin de traicionar a la Revolución Rusa. Pero no tienen ni idea de los problemas que ha de afrontar; ni de los peligros que amenazan a Rusia. [...] Si algo puede destruir mis simpatías hacia el régimen soviético, es el hecho de que resurjan las distinciones de clase. (Monk 328-329)

Ya en 1936 Wittgenstein retomó el dictado de sus clases en el Trinity College, dedicadas ese año al tema de los datos sensoriales y la experiencia personal. Por las noches, en íntimas veladas, dictaba en inglés a Francis los Cuadernos azul y marrón. Es en estos cuadernos, si no exactamente contemporáneos al menos inmediatamente posteriores a las Observaciones a los Cuadernos de Gramsci, en los que Wittgenstein utiliza por primera vez de modo explícito la expresión "juego de lenguaje". Juegos de lenguaje que emergen a partir del reconocimiento de la imposibilidad de la existencia de "el lenguaje". Juegos de lenguaje entrelazados por parecidos de familia que nos remiten a genealogías múltiples, diversas. Juegos de lenguaje que reclaman una metodología de estudio todavía por construir. En las observaciones, y una vez más de la mano de Gramsci, Wittgenstein avanza algunos pasos en la caracterización de este método:

El lenguaje no es algo teórico, sino práctico. Es práctica significativa, presupuesta en todas las demás. ¿ Filosofía de la praxis es entonces filosofía del lenguaje? Pero así como no es posible una filosofía de la lógica, tampoco es posible una filosofía del lenguaje. 
Gramsci se pregunta por el método de la filosofía de la praxis. Y creo que este método debe construirse como una modalidad de acercamiento al lenguaje: un modo de ver el lenguaje, de describirlo. (Observaciones 24 )

¿Podrían tal vez, esa descripción y esa mirada, asimilarse a las de un antropólogo que estudia tribus lejanas? El fragmento de Gramsci que inspira estas preguntas es transcripto íntegramente por Wittgenstein, a pesar de que este no se encuentra en el tomo que reúne las críticas al manual de Bujarin. Es posible, sin embargo, explicar este hecho teniendo en cuenta que los Cuadernos nunca se publicaron siguiendo el orden cronológico de su producción, sino aquel orden impuesto por una comisión especial del Partido Comunista Italiano dirigida por Palmiro Togliatti, que en la década del cuarenta decidió agrupar los escritos por su argumento, a fin de facilitar la lectura:

Dice Gramsci: “Toda verdad, incluso si es universal y también si puede ser expresada con una fórmula abstracta de tipo matemático (para la tribu de los teóricos) debe su eficacia al ser expresada en los lenguajes de las situaciones concretas particulares: si no es expresable en lenguas particulares es una abstracción bizantina y escolástica, buena para el solaz de los rumiadores de frases."

¿Es posible entonces que nos acerquemos a la tribu de los teóricos como antropólogos que buscan estudiar su lenguaje, sus costumbres y sus creencias? (Observaciones 32 )

De pronto sus manos que pasaban una a una las páginas - lentamente o no tanto, pero siempre al exacto ritmo de sus pensamientos - se detuvieron en una página precisa, aquella que consignaba la observación presentada con el número cuarenta y seis. Y la leyó en voz alta, varias veces, como si quisiera retenerla para siempre en su memoria:

Gramsci afirma: "La identidad de los términos no significa identidad de conceptos". Esto se entiende al examinar que idénticos términos usados en situaciones diversas presentan distintos significados. ¿Es entonces el uso lo que da significado a un término?

La regularidad en el uso del término fija el significado del concepto y fija en el mundo su referencia. Pero esta regularidad no es algo que pueda instituir un hombre solo. La regularidad en el uso tiene dimensión social. (Observaciones 35)

Las palabras resonaban todavía y advirtió al escucharlas como, junto con el manuscrito, había encontrado también el germen de esas ideas que posteriormente Wittgenstein expresaría del modo más sistemático que le era posible en sus Investigaciones filosóficas. El significado como uso, casi un eslogan impuesto a generaciones pero alejado de los estímulos que detonaron su emergencia, manifestaba por fin su verdadero arraigo. Y esta manifestación iluminaba a su vez ese otro plano significativo del texto, entrecruzado con el ya citado. A la construcción de una teoría social crítica y transformadora que hace de los lenguajes su objeto de estudio, a través de descripciones que buscan más modificar nuestra mirada que acertar explicaciones teóricas, se sumaba ahora esta clara afirmación de una posición materialista en relación con el significado y la verdad. Radicalización del materialismo -o supermaterialismo como avanzó en tono interrogativo Dominique Lecourt (70) - que, desde la práctica efectiva del lenguaje, busca conjurar los peligros del materialismo vulgar, criticado en esos años por Antonio Gramsci, en la soledad de su celda.

Con un suspiro, acarició una vez más el libro que pronto encontraría expuestas sus páginas a otras manos, y a otras lecturas sus palabras. Y como de lecturas se trataba, se detuvo aun para preguntarse quizás por primera vez en todos estos años - cómo hubiese deseado Wittgenstein ser leído. Seguramente no como él en su introducción lo presentaba, íntimamente vinculado al marxismo occidental y heterodoxo. Aunque no dudaba que algo muy profundo había unido a estos hombres - a Wittgenstein y a Gramsci- más allá de convicciones políticas o intereses teóricos.

Wittgenstein y Gramsci, ambos resistiendo en la escritura. Resistiendo la derrota y cubriendo con desesperación páginas y más páginas de cuadernos escolares, en las frías noches de trincheras o en la humedad de la cárcel. Escribiendo no para ser leídos, interpretados, despedazados y rearmados otra vez a gusto de cada quien. Sino escribiendo para sostener la existencia cuando ya ninguna mirada alcanzaba a rescatarlos del infierno o de la nada.

¿Cómo hubiese deseado Wittgenstein ser leído? Con la lectura de la resistencia, como también lo quiso Gramsci. Las breves y fragmentarias anotaciones de 
Gramsci que Sraffa le había acercado, alcanzaron para que Wittgenstein pudiera reconocer esa resistencia en su cuerpo y su escritura, tal como lo expresa en la última de las observaciones de los Cuadernos de cárcel:

Veo claro ahora que las palabras más auténticas no las escriben los hombres porque tienen ideas o pensamientos que transmitir. Las escriben por desesperación. Profunda desesperación que nos obliga a inventar cada día nuevos pensamientos e ideas para poder todavía escribir. (37)

Fue en ese instante que un par de golpes sobrios a la puerta lo sacudieron definitivamente de sus cavilaciones. Una voz anónima le recordó que el acto de presentación del libro comenzaba ya.

\section{Referencias}

Badiou, Alain. El ser y el acontecimiento. Buenos Aires: Manantial, 1999. Impreso.

Cacciari, Massimo. Krisis. Ensayo sobre la crisis del pensamiento negativo de Nietzsche a Wittgenstein. México: Siglo XXI, 1982. Impreso.

Lecourt, Dominique. El orden y los juegos. Buenos Aires: Ediciones de la Flor, 1984. Impreso.

Monk, Ray. Ludwig Wittgenstein, el deber de un genio. Barcelona: Anagrama, 1998. Impreso.

Moreno, Alberto. "Stanley Cavell y Thomas S. Kuhn". Actas del VII Congreso Nacional de Filosofía, (1994): 560-562. Impreso.

Pascal, Fania. Un recuerdo personal. Rees, Rush (comp.). México: Fondo de Cultura Económica, 1989. Impreso.

Rossi-Landi, Ferrucio. El lenguaje como trabajo y como mercado. Caracas: Monte Ávila Editores, 1970. Impreso.

Wittgenstein, Ludwig. "Observaciones a la Rama Dorada de Frazer". Wittgenstein, Ludwig. Ocasiones Filosóficas. Madrid: Cátedra, 1997. 144-163. Impreso.

Wittgenstein, Ludwig. Investigaciones filosóficas. Barcelona: Crítica, 1988. Impreso.

Wittgenstein, Ludwig Observaciones a los Cuadernos de Gramsci: Buenos Aires: Manifiesto Editorial, 2015. Impreso. 